sidered the local background. As it is the Beakers too often float in a vacuum. The reader will find it nearly impossible to grasp how they relate to regional cultural developments, for frequent allusions make it clear that Beakers were absorbed by local populations and adapted to suit local circumstances. Thus Myrhøj in Jutland is a "Bell Beaker settlement" (p.35), but only one house had Beakers. Local Late Neolithic pottery dominates, but where does it fit in? In Hungary, the Beaker is intrusive in local Vučedol contexts, while over the Eastern Beaker province as a whole "between $80 \%$ and $90 \%$ of all pottery found in Bell Beaker graves [sic] is not actually of a beaker shape at all [my italics], but small cups, jugs, bowls and jars". So why should these be "Bell Beaker graves" and Myrhøj a "Bell Beaker settlement"?

What is needed here, if ever we are to make sense of the Copper Age in Europe, is a radical change in thinking. These are not "Bell Beaker" graves and settlements, but the graves and settlements of whatever local cultural group is involved, which happen to incorporate Beakers and Beaker influence to varying degrees. Usually Harrison at least acknowledges a local cultural element, for example in southern France (pp.114-116), and especially in Italy (p.123), where recent discoveries offer a good chance of putting Beakers into proper perspective. Alas, in Britain and Ireland, Harrison opts for the traditional Beaker invaders. "Bell Beaker settlements", as at Newgrange and Knowth, are mentioned without making it clear that only a fraction of their pottery is classic Beaker; a lot of it is decidedly sui generis, and the rest local in character. For me, the treatment of Britain is particularly disappointing: the author fails to examine objections to a distinct Beaker physical type; he does not scrutinize critically the socalled Beaker innovations; and he appears not to appreciate the supreme importance of the Lanting and Van der Waals regional approach, not just for British Beakers, but for later British prehistory generally.

It would be churlish not to compliment the author on his choice of illustrations, which make clear the skill and patience which went into producing Beakers; and as a panoramic view of the variety of regional Beaker styles this book will be invaluable. But Harrison's aim is to "give an intelligible account of the Copper Age in Western Europe" (p.6) and he does not seriously attempt the task. It is a perilous time to write on the Beaker phenomenon, but suicidal not to have a clear idea in one's own mind beforehand of what Beakers are all about. I confess that I would not be so rash as entirely to dismiss the Wee Folk; but I have no such qualms about the "Beaker Folk",

Colin Burgess is Staff Tutor in Archaeology Department of Adult Education, University of Newcastle upon Tyne, and author of The Age of Stonehenge (Dent, 1980).

\title{
Mummies: new light on ancient societies
}

\section{A. Rosalie David}

An X-Ray Atlas of the Royal Mummies. Edited by James E. Harris and Edward F. Wente. Pp.403. ISBN 0-2263-1745-5. (Chicago University Press: 1980.) $\$ 55, £ 33$. Mummies, Disease and Ancient Cultures. Edited by Aidan and Eve Cockburn. Pp.360. ISBN 0-521-23020-9.(Cambridge University Press: 1980.) £25, \$45.95.

GRAFTON Elliot Smith, Armand Ruffer and Alfred Lucas led the field in the application of their disciplines - anatomy, histology and chemistry - to the study of ancient Egyptian mummified remains in the early part of this century. Since then, there has been a continuing interest in the use of medical and scientific techniques to amplify historical and literary knowledge of family relationships, the existence of disease, living conditions and funerary practices in this ancient civilization. Recent technological advances have encouraged further multi-disciplinary research, and the study of mummies has provided the Egyptologist with new information.

The discovery of the Egyptian royal mummies of the New Kingdom period (c. $1675-950 \mathrm{BC}$ ) was an archaeological find of considerable significance. The pharaohs and their queens, buried with great ceremony in rock-cut tombs at Thebes in Upper Egypt, were soon disturbed by robbers; their tombs were plundered and their mummies stripped of precious amulets. The high-priests of the god Amon re-buried many of these royal mummies in two resting places - the shaft of a tomb near Deir el-Bahri and a side chamber in a King's tomb in the Valley of the Kings - in the vicinity of Thebes. Here, they remained undisturbed until the chance discovery of the two caches in AD 1871 and AD 1898.

The mummies were subsequently removed to the Cairo Museum, where they were unwrapped and investigated by archaeologists and anatomists in 1889 and in 1912, when G. Elliot Smith produced his definitive anatomical work entitled The

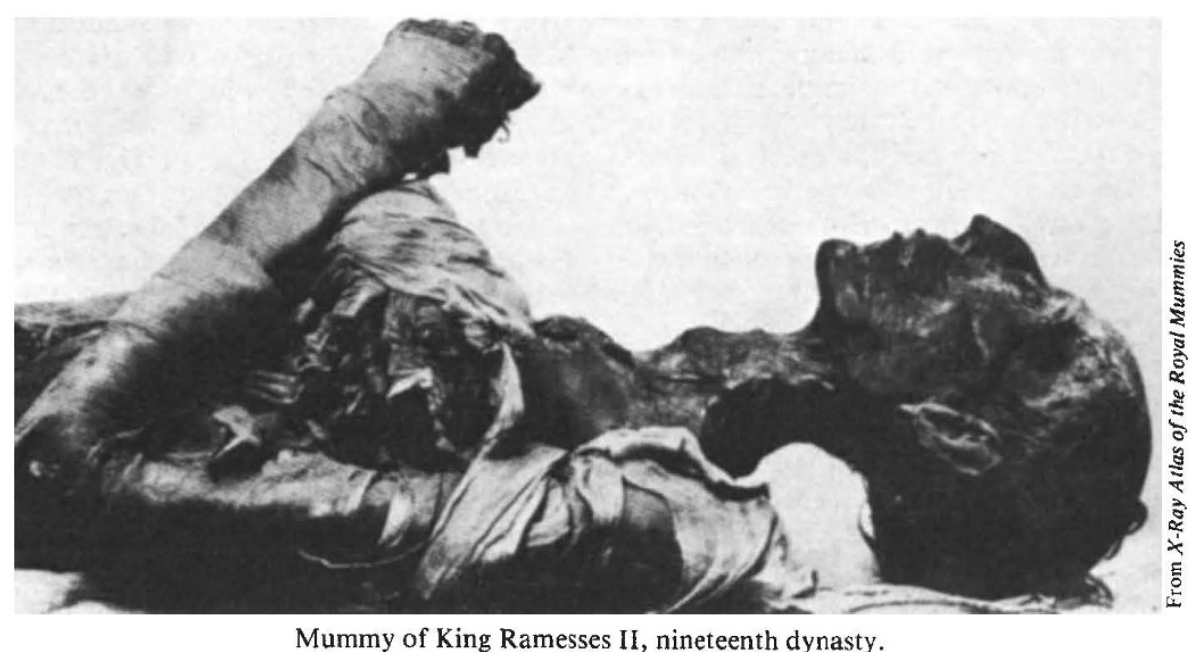

Royal Mummies. This included the examination of kings, queens, princes, princesses, priests and some unidentified individuals. However, having the opportunity to examine only one of these mummies with radiographic techniques, he stated that ". . . examination with the aid of X-rays would, no doubt, have provided much additional information and $I$ hope this will be done at some future time . . .".

This opportunity did not arise until 1967, when the University of Michigan, which had previously collaborated with Alexandria University in a radiographic survey of the skulls of an ancient Nubian people, was invited by the Egyptian authorities to $\mathrm{X}$-ray the royal mummies in the Cairo Museum.

Their aims were to add to historical and literary sources relating to the chronology of this period and to the lengths of the rulers' reigns; to assess the health of each individual; to check the reality of the royal sculpture and art forms against the physical evidence of the mummies; and, using a portable X-ray cephalometer, to determine the craniofacial variations and the degree of physical heterogeneity evident in the pharaohs and queens of the New Kingdom.

The Atlas provides the long-awaited reference work (a popular interim account by J. E. Harris and K. R. Weeks, X-Raying the Pharaohs, was by published in 1973 by Charles Scribner's Sons). It does not give a detailed description of each mummy, but, in addition to the illustrative material, uses a series of self-contained chapters to highlight features of this unique collection. The chapters reflect the individual interests of the multi-disciplinary team, and include techniques of mummification, the practice of medicine and dentistry in ancient Egypt, evidence of physical and dental disease in the royal mummies, radiological techniques and findings, the geneaology of the Royal Family and craniofacial variation, pharaohs (here, Egyptological and and the age at death of the New Kingdom 
physical evidence, sometimes at variance, is assessed separately). Such an approach, as admitted by the editors, results in a degree of repetition and an overlap of material in some instances. However, it is useful and interesting to see the physical and historical evidence summarized independently.

Another difficulty which the investigators faced, because of the paramount consideration for the safety of the royal mummies, was the necessity of examining the mummies in their modern wooden cases in the museum, instead of under near-ideal conditions in a modern radiology department where sophisticated equipment and a variety of radiological techniques would have been available. There is a consequent lack of quality in the $\mathrm{X}$-rays and possibly in the completeness of the evidence obtained.

However, some of the most interesting results included the observation that, unlike certain other Egyptian mummy collections, these royal mummies showed a marked degree of cultural and genetic heterogeneity. This reflected the presence of foreign princes and princesses in the Egyptian royal family of the New Kingdom rather than the averred custom of royal consanguineous marriages undertaken to ensure succession to the throne. Another tentative conclusion, reached through the use of scienctific techniques, was that a mummy known previously as the "Elder Lady" was in fact probably Queen Tiye, a close relative of Tutankhamun.

Nevertheless, the caution which historians should observe in utilizing the results of such scientific investigations is well illustrated by one of the conclusions drawn here. This concerns the proposed relationship between the pharaohs Amenhotep III and Tutankhamun. Previous investigations of the mummies attributed to these kings, undertaken by Professor R. G. Harrison and his colleagues, and based on palaeoserological and anatomical observations, had indicated that Amenhotep III was probably Tutankhamun's father. However, a different conclusion is drawn here: "The cephalometric X-ray records would not support the ... contention. It is most improbable that the mummy designated Amenhotep III was the biologic father of King Tutankhamun'.

The second book reviewed here, Mummies, Disease and Ancient Cultures, deals with a wider range of techniques and also shows how a variety of societies have preserved their dead, either unintentionally or by artificial methods, as "mummies". This study again shows the value of a multidisciplinary approach. In the long term, it is hoped that the work will go some way towards answering questions concerned with the origin of diseases and their evolution in different societies. To this end, the team is committed to a detailed pathological study of world-wide collections of mummies.
A summary is given of the work to date, and although Egyptian and South American mummies have received most detailed attention at present, a survey of other mummified remains is included those discovered in the United States, the Aleutian Islands, Alaska, the bog bodies of Denmark, mummies in Australia and Melanesia, and Japanese examples.

A complete section is devoted to reports of the techniques involved in this study which include physical anthropology, radiology, histology, electron microscopy, palaeoserology and palaeobiochemistry. Not only does the book illustrate the various methods - heat-drying, freezing or the application of dehydrating agents - by which a body can be preserved, but it also shows how diverse are the religious and environmental reasons which bring about mummification in different parts of the world.

Both books reflect a resurgent interest in the application of scientific techniques to the physical remains of ancient societies, which, used with due caution and appreciation of the possible fallability and limitations of such investigations, can provide the historian with a valuable additional insight.

Rosalie David is the Egyptologist at the Manchester Museum, University of Manchester, and Director of the Manchester Egyptian Mummv Research Project.

\section{The cradle of geology refurbished}

\section{John Sutton}

The Geology of Europe. By Derek V. Ager. Pp.560. ISBN 0-7084-115-2. (McGrawHill: 1980.) £16, \$38.40.

IN MY opinion this is much the best account of the geology of Europe to have appeared since Gignoux published his Géologie Stratigraphique over 50 years ago. Derek Ager describes his subject as Europe seen by a stratigrapher-palaeontologist. $\mathrm{He}$ treats his material very differently from Gignoux and the contrast is illuminating. Gignoux drew nine-tenths of his examples from Europe, and, in so doing, produced a comprehensive account of its geology which started with the oldest rocks, proceeded through younger formations to the most recent, providing abundant stratigraphical successions and the like on the way. Ager throws this approach out of the window; there is hardly a stratigraphical table in the book, so that he has space for much else.

Ager divides Europe into four regions on the basis of the relative ages of the last extensive period of metamorphism and deformation to have affected them. The geological history of each region is then described from start to finish - a method which brings out relations of older and younger events particularly well. Each of the four sections ends with a concluding chapter a few pages long. I was particularly struck with Ager's concise, five-page summary of Precambrian Europe. Although, as he puts it, "the Precambrian history of our continent is for the most part lost in the mists of metamorphism', he packs a telling account into that brief chapter.

The main virtue of this book is the way in which it brings together details to give a geological picture on a continental scale. Derek Ager has an interesting approach to geophysics; he appreciates "the hurricane of fresh air that new geophysical thoughts breathed into our subject". He goes on to write what is one of the best accounts of any continent, set out on precisely the scale which would make it possible to compare the geological history of basins and uplifted crystalline blocks with the results of geophysical surveys. Such comparison, however, he leaves to others. He gives a good defence of his treatment, and in his introduction makes the point that any additional matter has to be balanced by the omission of something else. However, in a second edition I would hope at least to see a discussion of outline gravity and magnetic maps, and an account of crustal thickness.

Of all the continents, Europe is probably the most difficult to handle. Its geology is discussed in 20 languages, it is criss-crossed by frontiers and its complexities are probably the most apparent of any continent. Ager sails through all these difficulties triumphantly. He has travelled the continent repeatedly, he lists friends and helpers in every country; he is bold in his summaries and he writes with great clarity, and is not afraid to say what he thinks is important. Personal touches abound; we hear about the view from his study window and the nature of the rock surmounting the Ager garden gate. Historical figures pop up from time to time: Drake's game of bowls and the sailing of the Pilgrim Fathers illuminate the account of Plymouth Hoe. Whether, in consequence, one remembers which stage of the Devonian outcrops below the turf is probably a matter of individual experience. I expect every reader will find some of the allusions obscure; there are plenty of traps for the translators who will certainly get to grips with this most useful book. Unless they know their Sherlock Holmes and Irish mythology, we may yet see chien de chasse des Basquervilles and Blarneystein among the faunal lists and formation names of the future.

John Sutton is Pro Rector and Professor of Geology at Imperial College, University of London. 